\title{
Variability in Estrogen-Metabolizing Genes and Their Association with Genomic Instability in Untreated Breast Cancer Patients and Healthy Women
}

\author{
Raquel Alves dos Santos, ${ }^{1}$ Ana Cláudia Teixeira, ${ }^{1}$ Mônica Beatriz Mayorano, ${ }^{1}$ \\ Hélio Humberto Angotti Carrara, ${ }^{2}$ Jurandyr Moreira de Andrade, ${ }^{2}$ \\ and Catarina Satie Takahashi, ${ }^{1,3}$ \\ ${ }^{1}$ Department of Genetics, Faculty of Medicine of Ribeirão Preto, University of São Paulo, Bloco G., Avenue Bandeirantes, 3900, \\ 14049-900 Ribeirão Preto, SP, Brazil \\ ${ }^{2}$ Department of Gynecology and Obstetrics, Faculty of Medicine of Ribeirão Preto, University of São Paulo, \\ 14049-900 Ribeirão Preto, SP, Brazil \\ ${ }^{3}$ Department of Biology, Faculty of Philosophy, Sciences and Letters of Ribeirão, University of São Paulo, \\ 14040-901 Ribeirão Preto, SP, Brazil
}

Correspondence should be addressed to Raquel Alves dos Santos, rasantos@rge.fmrp.usp.br

Received 17 February 2011; Accepted 17 April 2011

Academic Editor: Manoor Prakash Hande

Copyright (c) 2011 Raquel Alves dos Santos et al. This is an open access article distributed under the Creative Commons Attribution License, which permits unrestricted use, distribution, and reproduction in any medium, provided the original work is properly cited.

\begin{abstract}
In the present study, we investigated the relationship between polymorphisms in the estrogen-metabolizing genes CYP17, CYP1B1, CYP1A1, and COMT and genomic instability in the peripheral blood lymphocytes of $62 \mathrm{BC}$ patients and 62 controls considering that increased or prolonged exposure to estrogen can damage the DNA molecule and increase the genomic instability process in breast tissue. Our data demonstrated increased genomic instability in BC patients and that individuals with higher frequencies of MN exhibited higher risk to BC when belonging Val/Met genotype of the COMT gene. We also observed that CYP17 and CYP1A1 polymorphisms can modify the risk to $\mathrm{BC}$ depending on the menopause status. We can conclude that the genetic background in estrogen metabolism pathway can modulate chromosome damage in healthy controls and patients and thereby influence the risk to BC. These findings suggest the importance to ally biomarkers of susceptibility and effects to estimate risk groups.
\end{abstract}

\section{Introduction}

Breast cancer $(\mathrm{BC})$ is a prevalent cancer among women worldwide, and it has been estimated that there are 71 cases of BC per year for every 100000 women in Brazil. BC shows some distinctive features concerning age-specific incidence rates [1]. It is one of the most common causes of death among women, and epidemiological studies indicate that the age of onset is slowly, but steadily, becoming lower. This suggests that there may be changes in environmental factors that are affecting $\mathrm{BC}$ risk [2].

The risk factors for $\mathrm{BC}$ include early age of menarche, delayed menopause, contraceptive use, hormonal replacement therapy, above-average body mass index, exposure to environmental pollutants, smoking, and alcohol use [1-3]. However, it is generally believed that the initiation of $\mathrm{BC}$ is a consequence of cumulative genetic damage, which leads to genetic alterations that result in the activation of protooncogenes and the inactivation of tumor suppressor genes [4]. A large number of genetic variants that are associated with BC risk have been identified in genes involved in a wide variety of functions, including steroid hormone metabolism, detoxification of environmental carcinogens, DNA damage repair, and tumor suppression [5].

As observed in drug and chemical metabolism, there is considerable interindividual variability (i.e., polymorphisms) in the conjugation pathways of both estrogen and catechol estrogens. These person-to-person differences, 
TABLE 1: Characteristics of breast cancer patients and controls.

\begin{tabular}{lccc}
\hline & Patients $N(\%)$ & Controls $N(\%)$ & $P$ \\
\hline Smoking & & & \\
$\quad$ Yes & $14(22.5)$ & $22(35.4)$ & .1 \\
No & $48(77.5)$ & $40(64.6)$ & \\
Menopause status & & & \\
$\quad$ Post & $32(51.6)$ & $23(37)$ & .1 \\
Pre & $30(48.4)$ & $39(63)$ & \\
HRT & & & \\
Yes & $20(32.2)$ & $28(45.1)$ & .2 \\
No & $42(67.8)$ & $34(54.9)$ & \\
Full-term pregnancy & & & \\
Yes & $44(70.9)$ & $42(68.4)$ & .8 \\
No & $18(29.1)$ & $20(32.2)$ & \\
\hline
\end{tabular}

HRT: hormone replacement therapy.

which are attributed to polymorphisms in the genes encoding for the respective enzymes, may define subpopulations of women with higher lifetime exposure to hormonedependent growth promotion or to cellular damage from particular estrogens and/or estrogen metabolites [4].

Current evidence suggests that the metabolic byproducts of estrogens in the body may act as initiators of cellular alterations [6]. Estrogen metabolism products such as quinone-catecholestrogen can bind to DNA and form DNA adducts [7]. The generation of free radicals by metabolic redox cycling between quinone and hydroquinone can damage DNA by causing strand breaks, 8-hydroxylation of purines, and lipid hydroperoxide-mediated DNA modifications [8].

Although still controversial, a number of genes involved in biogenesis (CYP17), bioavailability (CYP1B1 and CYP1A1), and degradation (COMT) of estrogen compounds contain polymorphisms that could affect susceptibility to BC [9]. They are called low penetrance genes (or sometimes modifier genes) and are, in this instance, defined as genes in which subtle sequence variations or polymorphisms may be associated with a slightly to moderately increased relative risk for BC [4].

The hypothesis of the present study is that polymorphic variants of the estrogen metabolizing genes CYP17, CYP1B1, CYP1A1, and COMT may affect the spontaneous levels of chromosome damage in lymphocytes of $\mathrm{BC}$ patients and subsequently modulate $\mathrm{BC}$ risk.

Therefore, the objective of the present work was to correlate the genotypes of polymorphic variants of the above-mentioned genes with the basal levels of chromosome damage in lymphocytes of untreated BC patients and healthy individuals. Micronucleus assay was employed to determine the extent of baseline chromosome damage in $\mathrm{BC}$ patients and controls, and PCR-RFLP was used for genotype analysis.

\section{Patients and Methods}

2.1. Subjects. The BC patient group consisted of 62 untreated women diagnosed with in situ or invasive ductal breast carcinoma, ranging in age from 25 to 60 years old (mean age, 50.5 years old) and free of any pathology associated with the use of medication that is known to cause DNA damage. The control group consisted of 62 women with ages ranging from 25 to 50 years (mean age, 46.7-years old). They were enrolled in the control group after a detailed investigation in order to ensure that they were free from any breast pathology. They came from the same geographical location, their dietary habits were not appreciably different, and they were not occupationally exposed to genotoxic chemicals. None of the subjects reported alcohol consumption, the use of genotoxic medicine, presence of known inherited genetic disorders or chronic diseases or exposure to ionizing or nonionizing radiation, even for diagnostic or therapeutic purposes, for at least one month prior to enrolling in the study. Patients and controls enrolled in the present study did not report family history of breast and/or ovarian cancer. Characteristics of patients and controls are presented in Table 1. This investigation was approved by the National Ethics Committee (CONEP: 1217/2004) and was performed in accordance with ethical standards. Informed consent of patients and controls was obtained before inclusion in the study and sample collection.

2.2. Blood Sampling. Samples of venous blood $(10 \mathrm{~mL})$ were collected in heparinized and EDTA Vacutainer tubes (Becton Dickinson, NJ, USA) by venepuncture under sterile conditions. The samples were coded, immediately protected from direct light, and processed for genotyping and micronucleus assay.

2.3. Genotype Determination. Genomic DNA samples were obtained from blood lymphocytes using a Wizard Genomic DNA Purification Kit (Promega, Madison, WI). Isolated DNA was resuspended in Tris-EDTA buffer $(\mathrm{pH}$ 8.0) and stored at $-20^{\circ} \mathrm{C}$ until use.

The T1931C polymorphism of the CYP17 gene was determined by PCR-RFLP with the following primers: sense, $5^{\prime}$-CAAGGTGAAGATCAGGGTAG-3' and antisense, $5^{\prime}$-GCTAGGGTAAGCAGCAAGAG-3'. The $145 \mathrm{bp}$ product was digested overnight with $8 \mathrm{U}$ of the restriction enzyme MspA1I. The $\mathrm{T}$ allele remained intact, but the $\mathrm{C}$ allele was digested into 75 and $70 \mathrm{bp}$ fragments. The V432L polymorphism of the CYP1B1 gene was genotyped with the following primers: sense, $5^{\prime}$-TCACTTGCTTTTCTCTCTCC$3^{\prime}$ and antisense, 5'-AATTTCAGCTTGCCTCTTG- $3^{\prime}$. The $650 \mathrm{bp}$ product was digested overnight with $8 \mathrm{U}$ of the restriction enzyme AcuI. The Leu allele was digested into 350 and $300 \mathrm{bp}$ fragments. The genotypes of the T3205C polymorphism of the CYP1A1 gene were determined with the following primers: sense, $5^{\prime}$-TAGGAGTCTTGTCTCATGCCT$3^{\prime}$ and antisense, 5' -CAGTGAAGAGGTGTAGCCGCT- $3^{\prime}$. The $340 \mathrm{bp}$ PCR product was digested for $3 \mathrm{~h}$ with $5 \mathrm{U}$ of the restriction enzyme MspI. The $\mathrm{C}$ allele was digested into 200 and $140 \mathrm{bp}$ fragments, whereas the $\mathrm{T}$ allele remained intact. The genotypes of the V158M polymorphism of the gene COMT were determined with the following primers: sense, $5^{\prime}$-TACTGTGGCTACTCAGCTGT-3' and 
TABLE 2: The genotype frequencies of the CYP17, CYP1B1, CYP1A1, and COMT gene variants in breast cancer patients and controls, and after menopause.

\begin{tabular}{|c|c|c|c|c|c|c|}
\hline \multirow{2}{*}{ Genotype } & \multicolumn{2}{|c|}{ Breast cancer patients $(n=62)$} & \multicolumn{2}{|c|}{ Controls $(n=62)$} & \multirow{2}{*}{ OR (95\% CI) } & \multirow{2}{*}{$P$ value } \\
\hline & Number & Frequency & Number & Frequency & & \\
\hline \multicolumn{7}{|l|}{ CYP17 } \\
\hline \multicolumn{7}{|l|}{ Premenopause } \\
\hline TT & 16 & 0.25 & 22 & 0.35 & 1.0 (reference) & .81 \\
\hline $\mathrm{TC}+\mathrm{CC}$ & 14 & 0.23 & 17 & 0.27 & $1.1(0.4-2.9)$ & \\
\hline \multicolumn{7}{|l|}{ Postmenopause } \\
\hline TT & 11 & 0.18 & 16 & 0.26 & 1.0 (reference) & .01 \\
\hline $\mathrm{TC}+\mathrm{CC}$ & 21 & 0.34 & 7 & 0.12 & $4.3(1.3-13.7)$ & \\
\hline \multicolumn{7}{|l|}{ CYP1B1 } \\
\hline \multicolumn{7}{|l|}{ Premenopause } \\
\hline $\mathrm{Val} / \mathrm{Val}$ & 6 & 0.1 & 15 & 0.24 & 1.0 (reference) & .11 \\
\hline Val/Leu+Leu/Leu & 24 & 0.39 & 24 & 0.39 & $2.5(0.8-7.5)$ & \\
\hline \multicolumn{7}{|l|}{ Postmenopause } \\
\hline $\mathrm{Val} / \mathrm{Val}$ & 11 & 0.18 & 6 & 0.1 & 1.0 (reference) & .56 \\
\hline Val/Leu+Leu/Leu & 21 & 0.33 & 17 & 0.27 & $0.6(0.2-2.1)$ & \\
\hline \multicolumn{7}{|l|}{ CYP1A1 } \\
\hline \multicolumn{7}{|l|}{ Premenopause } \\
\hline $\mathrm{TT}$ & 16 & 0.25 & 36 & 0.58 & 1.0 (reference) & .0004 \\
\hline $\mathrm{TC}+\mathrm{CC}$ & 14 & 0.23 & 3 & 0.05 & $10.5(2.6-41.7)$ & \\
\hline \multicolumn{7}{|l|}{ Postmenopause } \\
\hline TT & 24 & 0.39 & 17 & 0.27 & 1.0 (reference) & 1.0 \\
\hline $\mathrm{TC}+\mathrm{CC}$ & 8 & 0.13 & 6 & 0.1 & $0.9(0.2-3.2)$ & \\
\hline \multicolumn{7}{|l|}{ COMT } \\
\hline \multicolumn{7}{|l|}{ Premenopause } \\
\hline $\mathrm{Val} / \mathrm{Val}$ & 10 & 0.16 & 24 & 0.38 & 1.0 (reference) & .02 \\
\hline Val/Met+Met/Met & 20 & 0.32 & 15 & 0.24 & $3.2(1.1-8.6)$ & \\
\hline \multicolumn{7}{|l|}{ Postmenopause } \\
\hline $\mathrm{Val} / \mathrm{Val}$ & 11 & 0.18 & 12 & 0.2 & 1.0 (reference) & .2 \\
\hline $\mathrm{Val} / \mathrm{Met}+\mathrm{Met} / \mathrm{Met}$ & 21 & 0.34 & 11 & 0.18 & $2.0(0.6-6.2)$ & \\
\hline
\end{tabular}

TABLE 3: Frequency of micronucleated cells in untreated breast cancer women and controls with different genotypes.

\begin{tabular}{|c|c|c|c|c|c|}
\hline \multirow{2}{*}{ Genotype } & \multicolumn{2}{|c|}{ Breast cancer patients $(n=62)$} & \multicolumn{2}{|c|}{ Controls $(n=62)$} & \multirow{2}{*}{$P$ value } \\
\hline & Number & CBMN $(\% 0)$ & Number & CBMN (\%o) & \\
\hline \multicolumn{6}{|l|}{ CYP17 } \\
\hline TT & 27 & $19 \pm 8.9$ & 38 & $9.3 \pm 6.3$ & $<.0001$ \\
\hline $\mathrm{TC}+\mathrm{CC}$ & 35 & $18.2 \pm 10.5$ & 24 & $9.6 \pm 5.4$ & $<.0001$ \\
\hline \multicolumn{6}{|l|}{ CYP1B1 } \\
\hline Val/Val & 17 & $18.7 \pm 10.5$ & 21 & $6.7 \pm 4.1$ & $<.0001$ \\
\hline Val/Leu+Leu/Leu & 45 & $18.5 \pm 9.6$ & 41 & $10.3 \pm 5.9$ & $<.0001$ \\
\hline \multicolumn{6}{|l|}{ CYP1A1 } \\
\hline $\mathrm{TT}$ & 40 & $19.5 \pm 10.2$ & 53 & $9.9 \pm 5.5$ & $<.0001$ \\
\hline $\mathrm{TC}+\mathrm{CC}$ & 22 & $16.7 \pm 9$ & 9 & $9.1 \pm 5.3$ & .001 \\
\hline \multicolumn{6}{|l|}{ COMT } \\
\hline $\mathrm{Val} / \mathrm{Val}$ & 21 & $15.2 \pm 8.7$ & 34 & $11.3 \pm 6.7$ & .07 \\
\hline Val/Met+Met/Met & 41 & $20.3 \pm 10$ & 28 & $8.5 \pm 4.9$ & $<.0001$ \\
\hline
\end{tabular}

MNF: micronucleus frequency; M: mean; SE: standard error; patients compared to controls. 
TABLE 4: Estrogen-metabolizing gene polymorphisms in breast cancer patients and controls with frequency of micronucleated cells higher than the mean of each group.

\begin{tabular}{|c|c|c|c|c|c|c|}
\hline \multirow{2}{*}{ Genotype } & \multicolumn{2}{|c|}{ Breast cancer patients $(n=27)$} & \multicolumn{2}{|c|}{ Controls $(n=26)$} & \multirow{2}{*}{ OR (95\% CI) } & \multirow{2}{*}{$P$ value } \\
\hline & Number & Frequency & Number & Frequency & & \\
\hline \multicolumn{7}{|l|}{ CYP17 } \\
\hline $\mathrm{TT}$ & 12 & 0.44 & 9 & 0.35 & 1.0 (reference) & .57 \\
\hline $\mathrm{TC}+\mathrm{CC}$ & 15 & 0.56 & 17 & 0.65 & $0.6(0.2-2.0)$ & \\
\hline \multicolumn{7}{|l|}{ CYP1B1 } \\
\hline $\mathrm{Val} / \mathrm{Val}$ & 6 & 0.22 & 3 & 0.12 & 1.0 (reference) & .46 \\
\hline Val/Leu+Leu/Leu & 21 & 0.78 & 23 & 0.88 & $0.46(0.1-2.0)$ & \\
\hline \multicolumn{7}{|l|}{ CYP1A1 } \\
\hline TT & 21 & 0.78 & 16 & 0.62 & 1.0 (reference) & .2 \\
\hline $\mathrm{TC}+\mathrm{CC}$ & 6 & 0.22 & 10 & 0.38 & $0.4(0.1-1.5)$ & \\
\hline \multicolumn{7}{|l|}{ COMT } \\
\hline $\mathrm{Val} / \mathrm{Val}$ & 6 & 0.22 & 13 & 0.5 & 1.0 (reference) & .04 \\
\hline $\mathrm{Val} / \mathrm{Met}+\mathrm{Met} / \mathrm{Met}$ & 21 & 0.78 & 13 & 0.5 & $3.5(1-11.4) \uparrow$ & \\
\hline
\end{tabular}

antisense, 5' -TGAAGCTGGTGTGAACACCT-3'. The 114 bp PCR product was digested with $5 \mathrm{U}$ of the restriction enzyme NlaIII. The Met allele was digested into fragments of 96, 54,39 , and $27 \mathrm{bp}$, whereas the Val allele was digested into fragments of 54 and 39 bp only.

2.4. Cell Culture and Cytokinesis-Block Micronucleus Assay. Lymphocyte cultures were prepared combining $0.5 \mathrm{~mL}$ of isolated lymphocytes in plasma with $5 \mathrm{~mL}$ of complete medium containing $78 \%$ of RPMI (Sigma-Aldrich Co., USA), 20\% inactivated fetal bovine serum (GibcoInvitrogen, Denmark), the antibiotics penicillin $(5 \mu \mathrm{g} / \mathrm{mL}$, Sigma-Aldrich Co., USA) and streptomycin $(10 \mu \mathrm{g} / \mathrm{mL}$, Sigma-Aldrich Co., USA), and 2\% phytohemagglutinin (Life Technologies, Grand Island, NY, USA) to stimulate cell proliferation. Cultures were incubated at $37^{\circ} \mathrm{C}$. After 44 hours of incubation, cytochalasin B (Sigma-Aldrich Co., USA) was added to the cultures to a final concentration of $4 \mu \mathrm{g} / \mathrm{mL}$, according to the method of Fenech and Morley [10]. One thousand binucleated cells were analyzed per individual and the frequency of binucleated cells micronucleated (BCMN) was determined according to the criteria described by Fenech [11].

2.5. Statistical Analysis. The Mann-Whitney statistical test was used to compare BCMN between patients and controls. The frequency of BCMN in different genotypes was analyzed with one-way ANOVA and the statistical differences between groups for BC risk was calculated using Fisher's exact test (two-tailed). Crude odds ratios (ORs) were calculated and are given with 95\% confidence intervals (CIs). Results were considered significant when $P<.05$.

\section{Results and Discussion}

Table 1 compares and shows the homogeneity of BC patients and control groups according to their smoking habits,

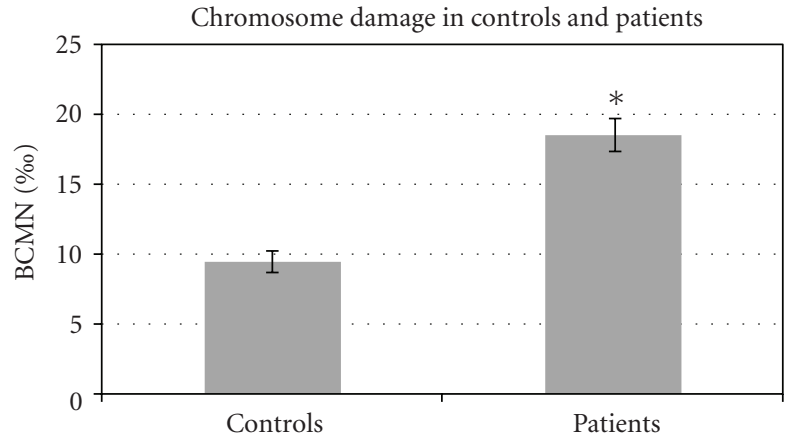

FIGURE 1: Frequency of BCMN in untreated BC women and healthy controls. A total of one thousand binucleated cells were analyzed for $\mathrm{MN}$ count in each of $62 \mathrm{BC}$ patients and 62 age-matched controls. Bars represent standard error of mean; ${ }^{*} P<.001$ significantly different from control group.

menopause status, hormone replacement therapy, and fullterm pregnancy. Basal level of chromosome damage was measured by micronucleus $(\mathrm{MN})$ assay in lymphocytes from 62 BC patients and 62 age-matched controls, as shown in Figure 1. BC patients exhibited higher levels of chromosome damage than controls according to $\operatorname{BCMN}(P<.05)$.

Table 2 shows the genotype distributions in patients and controls according to menopause status. The genotype distributions for all cases were in agreement with those predicted by the Hardy-Weinberg equilibrium. An association between $\mathrm{BC}$ occurrence and the $\mathrm{C}$ allele of the T1931C polymorphism in the CYP17 gene was observed in the postmenopause group (OR 4.3; 95\% CI 1.3-13.7). CYP1B1 V432L polymorphism had no association with BC occurrence in pre- and postmenopause women, however, in the premenopause women we observed increased risk to $\mathrm{BC}$ when the $\mathrm{C}$ allele of CYP1A1 gene (T3205C polymorphism) was present (OR 10.5; 95\% CI 2.6-41.7). COMT Met allele was also associated with $\mathrm{BC}$ occurrence in premenopause women (OR 3.2; 95\% CI 1.1-8.6). 


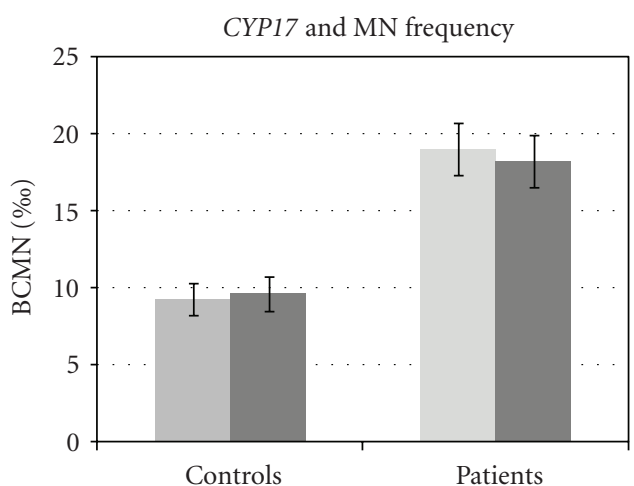

TT

$\mathrm{TC}+\mathrm{CC}$

(a)

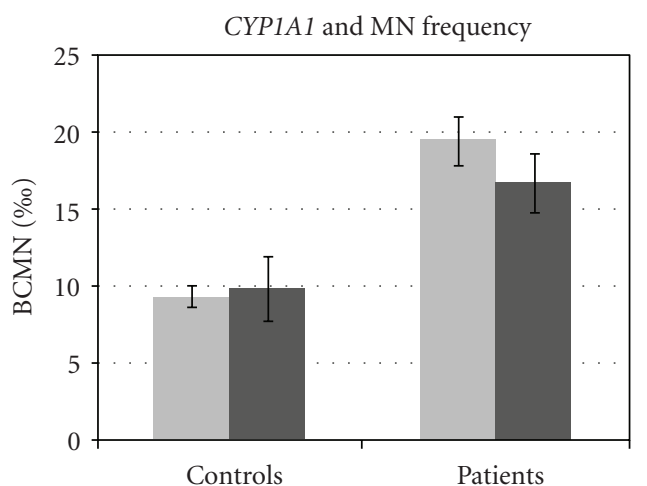

TT

$\mathrm{TC}+\mathrm{CC}$

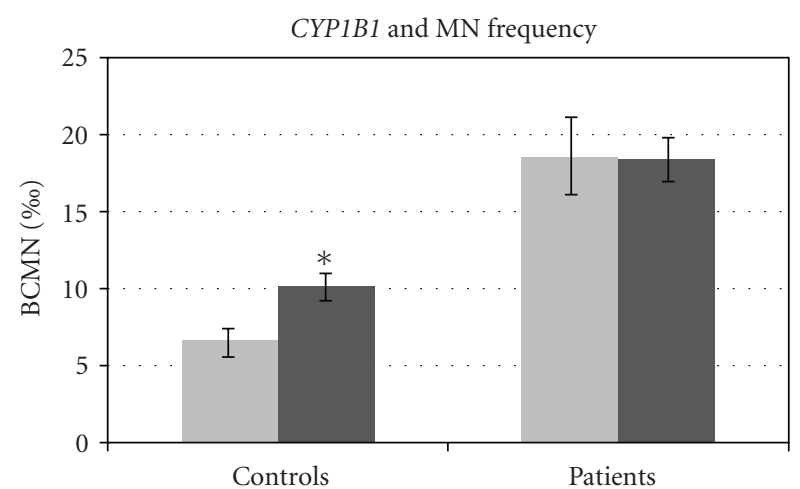

$\mathrm{Val} / \mathrm{Val}$

Val/Leu + Leu/Leu

(b)

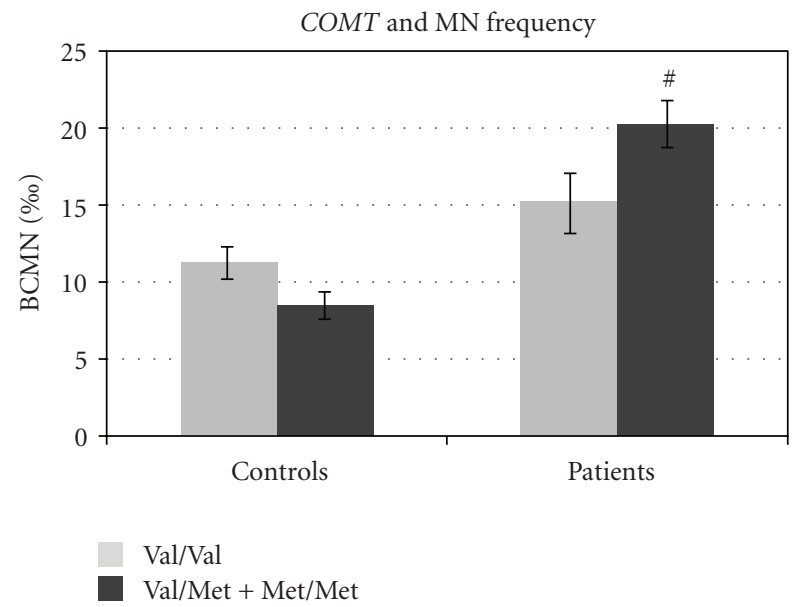

(d)

FIGURE 2: Frequency of BCMN in untreated BC women and healthy controls considering the presence of estrogen-metabolizing genes polymorphisms (a) CYP17, (b) CYP1B1, (c) CYP1A1, and (d) COMT. A total of one thousand binucleated cells were analyzed for MN count in each of 62 BC patients and 62 age-matched controls. Bars represent standard error of mean; ${ }^{*} P<.005$ significantly different from the wild type in the control group; ${ }^{\#} P<.005$ significantly different from the wild type in the patients group.

The basal levels of chromosome damage in $\mathrm{BC}$ patients and controls among the different genotypes are presented in Table 3. BCMN frequencies were higher in BC than in control group in all genotypes except for Val/Val of COMT gene where differences between patients and controls were not significant $(P=.07)$.

We also evaluated the influence of different genotypes considering the levels of chromosome damage in patient and control groups individually (Figure 2). CYP17 T1931C and CYP1A1 T3205C polymorphisms had no influence in the frequency of BCMN in patients as well as in controls. However, in control group, CYP1B1 432L allele was related to increased frequencies of BCMN $(P=.006)$. Differently, patients with V158M polymorphism of COMT gene presented higher frequencies of $\mathrm{BCMN}$ when compared to the wild-type counterparts $(P=.04)$.

Finally, we tested the risk to $\mathrm{BC}$ in the group of patients and controls that presented frequencies of BCMN higher than the mean (higher than 18.5 BCMN for patients and higher than 9.5 BCMN for controls) (Table 4). CYP17, CYP1B1, and CYP1A1 polymorphisms did not modify the occurrence of BC, however, COMT V158M polymorphism was more frequent in $\mathrm{BC}$ than in control group and resulted in significant OR increasing (OR 3.5; 95\% CI 1-11.4).

DNA damage can occur spontaneously or as consequence of exposure to chemical or physical genotoxins. There are modulators that can affect the levels of spontaneous DNA damage, including DNA repair genes, antioxidant defense genes, and estrogen-metabolizing gene polymorphisms that can lead to the accumulation of genotoxic estrogen subproducts. High serum estrogen levels are thought to be a major risk factor for $\mathrm{BC}$ [12]. In vitro and in vivo animal and patient-based studies suggest that estrogens, their metabolic compounds, and the entire biochemical metabolic machinery may play a role in $\mathrm{BC}$ carcinogenesis [13]. We can look forward into two different processes by 
which hormones are related to BC: (i) one involves the binding of estradiol to estrogen receptor (ER) alpha with the stimulation of cell proliferation. Errors in DNA occurring during replication result in fixed mutations when not well repaired; (ii) the other process results from the formation of genotoxic metabolites of estradiol, which can bind to DNA, cause depurination, and also result in mutations. Herein, we focused on the second process. Therefore, in the present study, the relationship between the SNPs in four estrogenmetabolizing genes and basal levels of chromosome damage was examined using lymphocytes of untreated BC women and healthy controls once lymphocytes can circulate for years or even decades, accumulating mutations in their DNA [14].

Results presented here show that the basal levels of chromosome damage detected by $\mathrm{MN}$ assay and observed in the control group are in accordance with those previously reported in other control populations of similar age $[15,16]$. It is well known that MN are formed by the condensation of acentric chromosomal fragments or by whole chromosomes lagging behind during cell division and that this is the only biomarker that allows the evaluation of both clastogenic and aneuploidogenic effects in a vast range of cells, as they are detected in interphase [17]. As we did not observe any statistical difference between smoking and nonsmoking patients or controls (data not shown), we grouped these two subsets together for the analysis of the basal levels of chromosome damage in patients and controls.

The investigation of basal levels of chromosome damage in peripheral lymphocytes of untreated cancer subjects has been previously reported. Baseline levels of DNA damage were significantly higher in bladder cancer patients than in controls [18], and the frequency of MN in stimulated peripheral blood cells from an untreated leukemia population was significantly greater than that in the control group [19]. Similar results were found by Lou et al. [14], who simultaneously investigated both baseline and ionizing radiationinduced (IR) genetic damage in peripheral lymphocytes from 36 cancer patients using MN and comet assays. They found that both spontaneous and IR-induced genetic damages were higher in patients than in controls.

In the present study, the primary objective was to investigate the relationship between the genotypes of polymorphisms in estrogen-metabolizing genes and the extent of endogenous chromosome damage. Although this is not an epidemiological study, the odds ratio for the different genotypes was also examined and displayed interesting findings.

The results presented here show that there is a slight significant relationship between the CYP17 polymorphism, and $\mathrm{BC}$ risk is postmenopausal women, however, we found no correlation between spontaneous chromosome damage and the T1931C polymorphism of CYP17 gene, which encodes for cytochrome $450 \mathrm{C} 17 \alpha$, a $17 \alpha$-hydroxylase that catalyzes the conversion of pregnenolone and progesterone to $17-\mathrm{OH}-$ pregnenolone and 17-OH-progesterone, respectively [20]. Cytochrome $\mathrm{p} 450 \mathrm{C} 17 \alpha$ also has a 17,20 -lyase activity that converts hydroxylase products to dehydroepiandrosterone (DHEAS) and androstenedione, respectively, which can be further converted to estrogens and testosterone [20]. It has been hypothesized that certain genotype variants in the CYP17 gene result in higher hormone levels, leading to an increased risk of BC. However, non-Hispanic white women who were heterozygous or homozygous for the variant allele of CYP17 had lower estrone, total testosterone, free testosterone, and DHEAS concentrations compared to women homozygous for the wild-type allele [21]. Chen and Pei [22] applied both traditional meta-analysis and Bayesian approach to determine the overall effect of CYP17 T1931C polymorphism on risk of $\mathrm{BC}$ and detected that carriers of $\mathrm{C}$ allele were positively associated with risk of $\mathrm{BC}$ in postmenopausal women and were inversely related to $\mathrm{BC}$ in pre-menopausal women.

The V432L polymorphism of the CYP1B1 gene is located within a catalytic heme-binding domain in exon 3 [23] and has been analyzed in several independent studies that present controversial results. Chinese women with the Leu/Leu genotype at the $\mathrm{L} 432 \mathrm{~V}$ polymorphism had a higher risk of $\mathrm{BC}(\mathrm{OR}=2.0,95 \% ; \mathrm{CI}=1.0-3.7)[24]$. A positive association was also seen in Turkish women but was limited to those with a high body mass index $(\mathrm{OR}=2.3,95 \%$; $\mathrm{CI}=1.3-4.2)$ [25]. In contrast, results presented here showed no association between V432L polymorphism and $\mathrm{BC}$ occurrence in preor postmenopause women (OR 2.5, 95\% CI 0.8-7.5 and OR $0.6,95 \%$ CI $0.2-2.1$, resp.). A significant inverse association between the Val allele and $\mathrm{BC}$ risk was previously observed in studies of African American or mixed populations [26]. It is interesting to note that in the control group, carriers of the Leu allele exhibited higher levels of DNA damage compared to homozygous wild-type individuals while this was not observed in the patients group. We believe that this difference between patients and controls is mostly due to the increased spontaneous levels of chromosome damage in $\mathrm{BC}$ which makes it difficult to identify suitable differences in BCMN between polymorphic and wild-type individuals. It has been described that CYP1B1 catalyzes $\mathrm{C} 4$ hydroxylation of estradiol (4-hydroxyestradiol $\left(4-\mathrm{OHE}_{2}\right)$ ). This metabolite can undergo metabolic redox cycling to generate free radicals such as superoxide and chemically reactive estrogen semiquinone/quinone intermediates, which can form DNA adducts [27, 28]. Anyway, these results suggest further investigation of this polymorphism combined with other low-penetrance gene polymorphisms such as DNA repair in the modulation of spontaneous chromosome damage in healthy women.

Cytochrome P450 1A1 (CYP1A1) is one of the most important phase I enzymes expressed in breast tissue. It catalyzes estrogen 2-hydroxylation, generating the 2-OH estrogen metabolite, which can form DNA adducts [28, 29]. The $3205 \mathrm{~T} \rightarrow \mathrm{C}$ polymorphism in CYP1A1 is located in the $3^{\prime}$ noncoding region and can affect the modulation of enzymatic activity and thereby the susceptibility risk to $\mathrm{BC}$ [30]. The results presented here showed that the frequency of this polymorphism was higher in premenopause $\mathrm{BC}$ women than in controls and resulted in association to $\mathrm{BC}$ risk (OR 10.5, 95\% CI 2.6-41.7), however, it had no effect on the frequency of BCMN in patients or in control group. The rare CT and CC genotypes were detected in 14 patients and three controls, and it, therefore, resulted in an extensive 
confidence interval (CI). Similar results were observed by Taioli et al. [30] that demonstrated an association between this polymorphism and $\mathrm{BC}$ cancer risk in African American women (OR $=9.795 \%$, CI 2.0-47.9), and Huang et al. [31] demonstrated the same association in Taiwanese women. Nevertheless, the association observed here must be interpreted with caution considering the number of individuals included in the present study and the fact that $\mathrm{C}$ allele is rare.

The catechol-O-methyltransferase (COMT) catalyzes the addition of a methyl group to reactive catechol estrogens, converting them into stable methyloxyestrogen conjugates [32]. In patients group, carriers of Met allele of the COMT gene exhibited higher levels of chromosome damage relative to those homozygous for the wild-type allele. Besides, when the analysis considered the association of $\mathrm{BC}$ occurrence in individuals that exhibited levels of chromosome damage higher than the mean, Met allele was strongly associated with $\mathrm{BC}$ occurrence. This was an interesting finding especially if we consider that biomarkers of susceptibility and risk contribute to the identification of high-risk subgroups of the population, independent of whether they are associated with previous exposure or they are involved in a defined pathway or mechanism [33]. It is known that G to A polymorphism at codon 108 in the COMT gene leads to a substitution of methionine to valine, resulting in decreased enzymatic activity and increased thermolability [34, 35]. As metabolites of catechol estrogens have the potential to induce oxidative DNA damage and form DNA adducts, the conversion of catechol estrogens into stable conjugates may be important in preventing $\mathrm{BC}$ [32]. In a previous study of a Taiwanese population, a strong association between the COMT polymorphism and $\mathrm{BC}$ risk was observed $(\mathrm{OR}=3.5$ 95\%, CI 1.15-13.3) [31].

The correlation between genetic polymorphisms and specific phenotypes was evaluated by Synowiec et al. [36]. They correlated a polymorphism in a DNA repair gene with oxidative DNA damage in $41 \mathrm{BC}$ patients and 48 controls. They demonstrated a strong association between $\mathrm{BC}$ occurrence and the $\mathrm{C} / \mathrm{C}$ genotype of the RAD51135G/C polymorphism, the Ser/Ser genotype of the OGG1Ser326Cys polymorphism and the Lys/Gln genotype of the XPD-Lys751Gln polymorphism. In contrast, the G/C genotype of the RAD-135G/C polymorphism and the Lys/Lys genotype of the XPD-Lys751Gln polymorphism exhibited a protective effect against $\mathrm{BC}$. In this study, the risk of $\mathrm{BC}$ was calculated in patients and controls that had higher levels of endogenous oxidative DNA damage.

We previously reported that Brazilian untreated BC patients exhibited higher levels of chromosome damage than healthy controls [37] and that XRCC3 polymorphism was weakly associated with the risk to $\mathrm{BC}$ in those individuals that presented higher levels of chromosome damage [38]. It is well known that DNA damage as detected in peripheral blood represents a surrogate for what would be observed in breast tissue. While the polymorphisms are obviously expressed in both breast tissue and lymphocytes, the level of expression of the genes and in particular, the level of substrate that in our present hypothesis is estradiol, may be and is likely very different within breast tissue and the lymphocytes, however, genome damage in lymphocytes may be correlated with cancer-initiating events in target tissues via a common genetic, dietary, or environmental factor [39]. Therefore, the manifestation of effects of the polymorphisms on levels of the reactive quinones may be quite different in breast tissue and lymphocytes, making extrapolation of the findings being reported to implications for $\mathrm{BC}$ quite tenuous. As mentioned above, this is not an epidemiological study and although the limited number of participants, we consider that our results point that polymorphisms in the enzymes involved in the metabolism of estradiol/estrone to reactive quinones that cause DNA damage may represent low penetrance risk factors susceptible of further detailed investigations.

\section{Conclusions}

It is unknown whether the healthy controls and patients with BC had equal levels of DNA damage before the appearance of clinical symptoms in the patients. It is also unclear whether $\mathrm{MN}$ enhancement is a consequence or causative agent of the disease process [19]. However, the followup of those controls who are carriers of Met allele of CYP1B1 gene that exhibited higher frequencies of BNMN than wild-type counterparts could help to further answer this question.

In conclusion, according to the data presented here both the genetic background of genes involved estrogen metabolism and DNA damage in healthy controls and patients can modulate BC risk reflected by higher chromosomal damage in lymphocytes.

\section{Conflict of Interests}

The authors declare no conflict of interests.

\section{Acknowledgments}

The authors gratefully acknowledge the cooperation of all volunteers who participated in this study. This investigation was supported in part by the Conselho Nacional de Desenvolvimento Científico e Tecnológico-CNPq (Grant no. 400887/2005 and 3473493/2004-7) and Coordenação de Aperfeiçoamento de Pessoal de Nível Superior-CAPES for fellowship to RA Santos and MB Mayorano.

\section{References}

[1] B. S. Hulka and P. G. Moorman, "Breast cancer: hormones and other risk factors," Maturitas, vol. 38, no. 1, pp. 103-116, 2001.

[2] V. N. Kristensen and A. L. Borresen-Dale, "Molecular epidemiology of breast cancer: genetic variation in steroid hormone metabolism," Mutation Research, vol. 462, no. 2-3, pp. 323-333, 2000.

[3] H. J. Kang, S. W. Kim, H. J. Kim et al., "Polymorphisms in the estrogen receptor-alpha gene and breast cancer risk," Cancer Letters, vol. 178, no. 2, pp. 175-180, 2002.

[4] K. Mitrunen and A. Hirvonen, "Molecular epidemiology of sporadic breast cancer: the role of polymorphic genes 
involved in oestrogen biosynthesis and metabolism," Mutation Research, vol. 544, no. 1, pp. 9-41, 2003.

[5] A. M. Dunning, C. S. Healey, P. D. P. Pharoah, M. D. Teare, B. A. J. Ponder, and D. F. Easton, "A systematic review of genetic polymorphisms and breast cancer risk," Cancer Epidemiology Biomarkers and Prevention, vol. 8, no. 10, pp. 843-854, 1999.

[6] J. D. Yager and N. E. Davidson, "Estrogen carcinogenesis in breast cancer," New England Journal of Medicine, vol. 354, no. 3, pp. 228-282, 2006.

[7] N. R. Bianco, G. Perry, M. A. Smith, D. J. Templeton, and M. M. Montano, "Functional implications of antiestrogen induction of quinone reductase: inhibition of estrogen-induced deoxyribonucleic acid damage," Molecular Endocrinology, vol. 17, no. 7, pp. 1344-1355, 2003.

[8] D. Roy and J. G. Liehr, "Estrogen, DNA damage and mutations," Mutation Research, vol. 424, no. 1-2, pp. 107-115, 1999.

[9] X. Yuan, G. Zhou, Y. Zhai et al., "Lack of association between the functional polymorphisms in the estrogen-metabolizing genes and risk for hepatocellular carcinoma," Cancer Epidemiology Biomarkers and Prevention, vol. 17, no. 12, pp. 36213627, 1999.

[10] M. Fenech and A. A. Morley, "Measurement of micronuclei in lymphocytes," Mutation Research, vol. 147, no. 1-2, pp. 29-36, 1985.

[11] M. Fenech, "The in vitro micronucleus technique," Mutation Research, vol. 455, no. 1-2, pp. 81-95, 2000.

[12] T. J. Key, N. E. Allen, E. A. Spencer, and R. C. Travis, "The effect of diet on risk of cancer," Lancet, vol. 360, no. 9336, pp. 861-868, 2002.

[13] B. Zumoff, "Does postmenopausal estrogen administration increase the risk of breast cancer? Contributions of animal, biochemical, and clinical investigative studies to a resolution of the controversy," Proceedings of the Society for Experimental Biology and Medicine, vol. 217, no. 1, pp. 30-37, 1998.

[14] J. Lou, J. He, W. Zheng et al., "Investigating the genetic instability in the peripheral lymphocytes of 36 untreated lung cancer patients with comet assay and micronucleus assay," Mutation Research, vol. 617, no. 1-2, pp. 104-110, 2007.

[15] C. Bolognesi, C. Lando, A. Forni et al., "Chromosomal damage and ageing: effect on micronuclei frequency in peripheral blood lymphocytes," Age and Ageing, vol. 28, no. 4, pp. 393397, 1999.

[16] D. Varga, J. Hoegel, C. Maier et al., "On the difference of micronucleus frequencies in peripheral blood lymphocytes between breast cancer patients and controls," Mutagenesis, vol. 21, no. 5, pp. 313-320, 2006.

[17] S. Pastor, A. Creus, T. Parrón et al., "Biomonitoring of four European populations occupationally exposed to pesticides: use of micronuclei as biomarkers," Mutagenesis, vol. 18, no. 3, pp. 249-258, 2003.

[18] M. B. Schabath, M. R. Spitz, H. B. Grossman et al., "Genetic instability in bladder cancer assessed by the comet assay," Journal of the National Cancer Institute, vol. 95, no. 7, pp. 540 547, 2003.

[19] Z. Hamurcu, H. Dönmez-Altuntas, and T. Patiroglu, "Basal level micronucleus frequency in stimulated lymphocytes of untreated patients with leukemia," Cancer Genetics and Cytogenetics, vol. 180, no. 2, pp. 140-144, 2008.

[20] L. Sharp, A. H. Cardy, S. C. Cotton, and J. Little, "CYP17 gene polymorphisms: prevalence and associations with hormone levels and related factors. A HuGE review," American Journal of Epidemiology, vol. 160, no. 8, pp. 729-740, 2004.

[21] P. E. Abrahamson, S. S. Tworoger, E. J. Aiello et al., "Associations between the CYP17, CYPIB1, COMT and SHBG polymorphisms and serum sex hormones in post-menopausal breast cancer survivors," Breast Cancer Research and Treatment, vol. 105, no. 1, pp. 45-54, 2007.

[22] Y. Chen and J. Pei, "Factors influencing the association between CYP17 T34C polymorphism and the risk of breast cancer: meta-regression and subgroup analysis," Breast Cancer Research and Treatment, vol. 122, no. 2, pp. 471-481, 2010.

[23] L. R. Bailey, N. Roodi, W. D. Dupont, and F. F. Parl, "Association of cytochrome P450 1B1 (CYP1B1) polymorphism with steroid receptor status in breast cancer," Cancer Research, vol. 58, no. 22, pp. 5038-5041, 1998.

[24] W. Zheng, D. W. Xie, F. Jin et al., "Genetic polymorphism of cytochrome P450-1B1 and risk of breast cancer," Cancer Epidemiology Biomarkers and Prevention, vol. 9, no. 2, pp. 147$150,2000$.

[25] N. A. Kocabas, S. Sardas, S. Cholerton, A. K. Daly, and A. E. Karakaya, "Cytochrome P450 CYP1B1 and catechol O-methyltransferase (COMT) genetic polymorphisms and breast cancer susceptibility in a Turkish population," Archives of Toxicology, vol. 76, no. 11, pp. 643-649, 2002.

[26] V. Paracchini, S. Raimondi, I. T. Gram et al., "Meta- and pooled analyses of the cytochrome P-450 1B1 Val432Leu polymorphism and breast cancer: a HuGE-GSEC review," American Journal of Epidemiology, vol. 165, no. 2, pp. 115-125, 2007.

[27] B. T. Zhu and A. H. Conney, "Functional role of estrogen metabolism in target cells: Review and perspectives," Carcinogenesis, vol. 19, no. 1, pp. 1-27, 1998.

[28] Y. Miyoshi and S. Noguchi, "Polymorphisms of estrogen synthesizing and metabolizing genes and breast cancer risk in Japanese women," Biomedicine and Pharmacotherapy, vol. 57, no. 10 , pp. 471-481, 2003.

[29] C. Chen, Y. Huang, Y. Li, Y. Mao, and Y. Xie, "Cytochrome P450 1A1 (CYP1A1) T3801C and A2455G polymorphisms in breast cancer risk: a meta-analysis," Journal of Human Genetics, vol. 52, no. 5, pp. 423-435, 2007.

[30] E. Taioli, H. L. Bradlow, S. V. Garbers et al., "Role of estradiol metabolism and CYP1A1 polymorphisms in breast cancer risk," Cancer Detection and Prevention, vol. 23, no. 3, pp. 232237, 1999.

[31] C. S. Huang, H. D. Chern, K. J. Chang, C. W. Cheng, S. M. Hsu, and C. Y. Shen, "Breast cancer risk associated with genotype polymorphism of the estrogen-metabolizing genes CYP17, CYP1A1, and COMT: A multigenic study on cancer susceptibility," Cancer Research, vol. 59, no. 19, pp. 4870-4875, 1999.

[32] M. M. Gaudet, S. Chanock, J. Lissowska et al., "Comprehensive assessment of genetic variation of catechol-O- methyltransferase and breast cancer risk," Cancer Research, vol. 66, no. 19, pp. 9781-9785, 2006.

[33] P. Boffetta, "Biomarkers in cancer epidemiology: an integrative approach," Carcinogenesis, vol. 31, no. 1, pp. 121-126, 2009.

[34] T. Lotta, J. Vidgren, C. Tilgmann et al., "Kinetics of human soluble and membrane-bound catechol O- methyltransferase: a revised mechanism and description of the thermolabile variant of the enzyme," Biochemistry, vol. 34, no. 13, pp. 42024210, 1995.

[35] H. M. Lachman, D. F. Papolos, T. Saito, Y. M. Yu, C. L. Szumlanski, and R. M. Weinshilboum, "Human catechol-Omethyltransferase pharmacogenetics: description of a functional polymorphism and its potential application to neuropsychiatric disorders," Pharmacogenetics, vol. 6, no. 3, pp. 243-250, 1996. 
[36] E. Synowiec, J. Stefanska, Z. Morawiec, J. Blasiak, and K. Wozniak, "Association between DNA damage, DNA repair genes variability and clinical characteristics in breast cancer patients," Mutation Research, vol. 648, no. 1-2, pp. 65-72, 2008.

[37] R. A. Santos, A. C. Teixeira, M. B. Mayorano, H. H. A. Carrara, J. M. Andrade, and C. S. Takahashi, "Basal levels of DNA damage detected by micronuclei and comet assays in untreated breast cancer patients and healthy women," Clinical and Experimental Medicine, vol. 10, pp. 87-92, 2010.

[38] R. A. Santos, A. C. Teixeira, M. B. Mayorano, H. H. A. Carrara, J. M. Andrade, and C. S. Takahashi, "DNA repair genes XRCC1 and XRCC3 polymorphisms and their relationship with the level of micronuclei in breast cancer patients," Genetics and Molecular Biology, vol. 33, no. 4, pp. 637-640, 2010.

[39] S. Bonassi, A. Znaor, M. Ceppi et al., "An increased micronucleus frequency in peripheral blood lymphocytes predicts the risk of cancer in humans," Carcinogenesis, vol. 28, no. 3, pp. 625-631, 2007. 

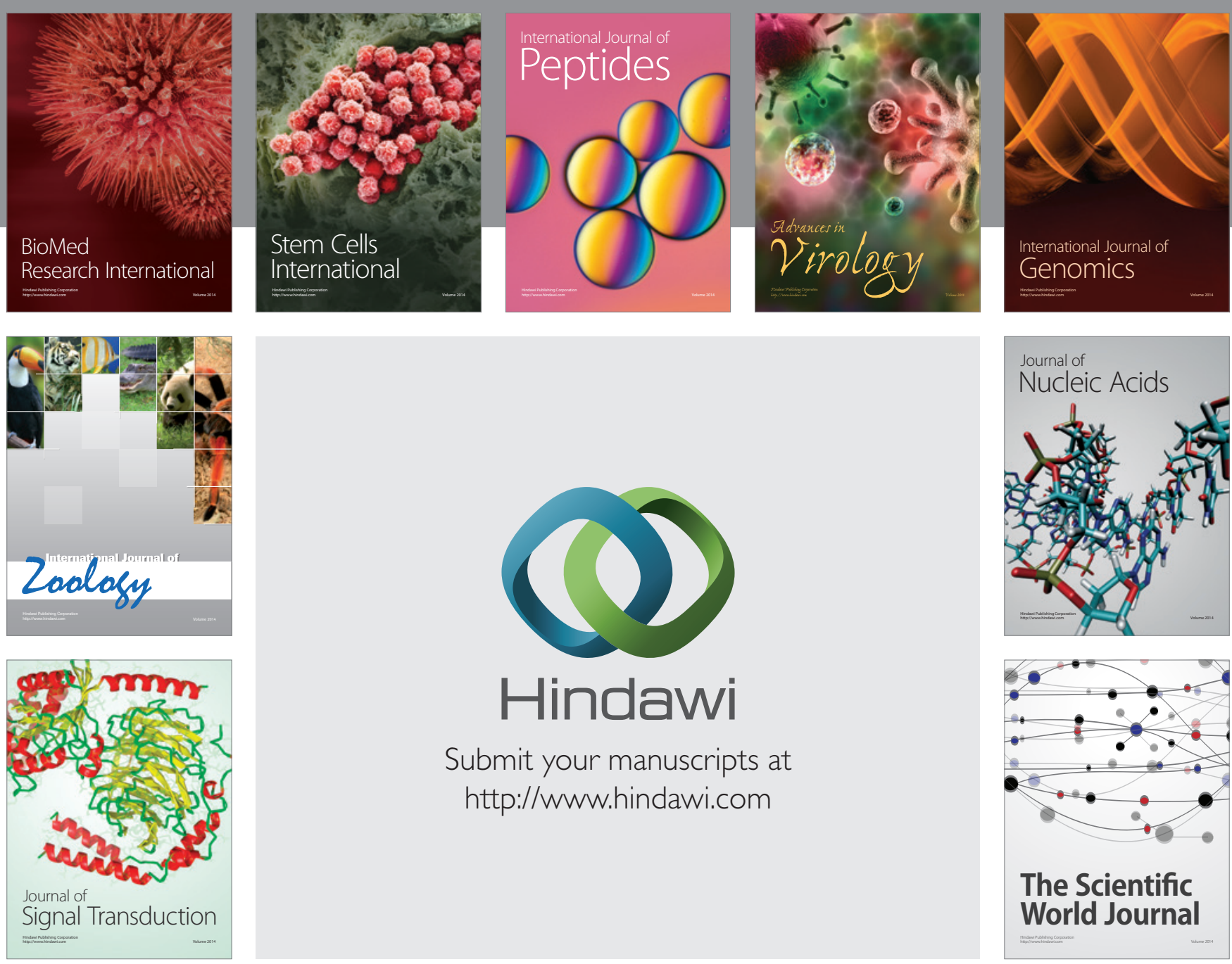

Submit your manuscripts at

http://www.hindawi.com
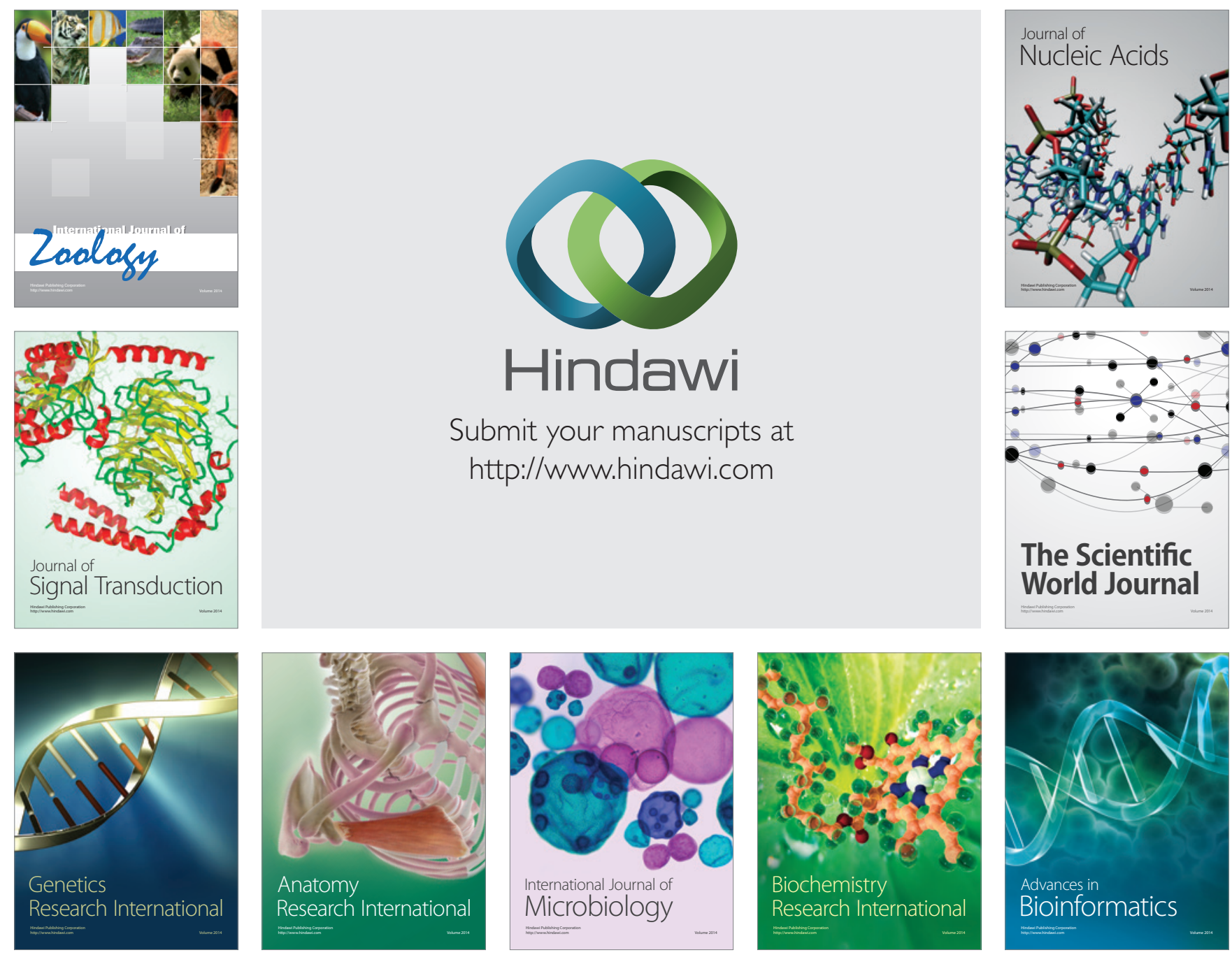

The Scientific World Journal
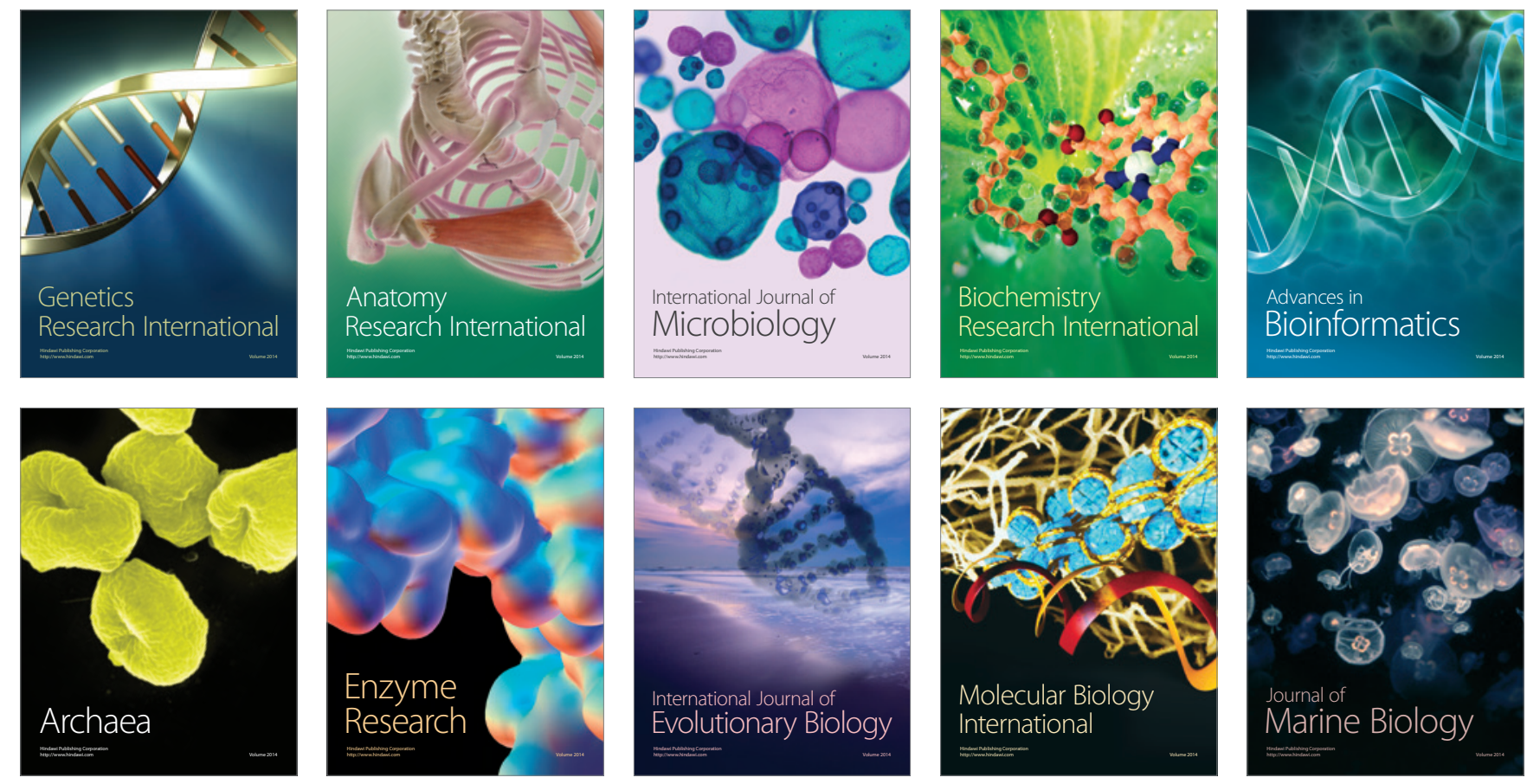